\title{
The complex life of DICKKOPF-1 in cancer cells
}

\author{
José Manuel González-Sancho ${ }^{1,2}$, Federico Rojo ${ }^{3}$, Alberto Muñoz ${ }^{1}$ \\ ${ }^{1}$ Departamento de Biología del Cáncer, Instituto de Investigaciones Biomédicas “Alberto Sols”, Consejo Superior de Investigaciones \\ Científicas (CSIC) - Universidad Autónoma de Madrid (UAM), Madrid, E-28029, Spain \\ ${ }^{2}$ Departamento de Bioquímica, Facultad de Medicina, Universidad Autónoma de Madrid, Madrid, E-28029, Spain \\ ${ }^{3}$ Departamento de Anatomía Patológica, Instituto de Investigación Sanitaria - Fundación Jiménez Díaz, Madrid, E-28040, Spain
}

Correspondence: Alberto Muñoz

E-mail: amunoz@iib.uam.es

Received: June 15, 2015

Published online: July 06, 2015

\begin{abstract}
The role of DICKKOPF (DKK)-1 in human cancer is controversial. DKK-1 behaves as an inhibitor of the canonical Wnt/ $\beta$-catenin signaling pathway acting at the plasma membrane, although several studies have proposed effects that are independent of the inhibition of $\beta$-catenin transcriptional activity, in some cases mediated by the activation of c-Jun N-terminal kinase (JNK). Recently, a proportion of DKK-1 protein has been found within the nucleus of human intestinal epithelial cells following an apical-to-basal crypt decreasing gradient, and in that of colon carcinoma cells. Moreover, we show here that in the human mammary gland DKK-1 is also present within the nucleus of many differentiated luminal epithelial cells and in that of a small proportion of myoepithelial cells. Nuclear DKK-1 binds to actively transcribed chromatin and regulates the expression of specific genes, some of which are involved in cell proliferation, survival and stemness, and in the defense against xenobiotics. This may explain the finding that while DKK-1 is downregulated more rapidly in the nucleus than in the cytosol during colon carcinoma progression, its expression remains high in a percentage of patients who do not respond to chemotherapy. Available data suggest that the accumulation of DKK-1 in the nucleus of colon carcinoma cells depends on signals from the surrounding tumor microenvironment.
\end{abstract}

Keywords: DICKKOPF1; DKK-1; colon cancer; breast cancer; Wnt; $\beta$-catenin

To cite this article: José Manuel González-Sancho, et al. The complex life of DICKKOPF-1 in cancer cells. Can Cell Microenviron 2015; 2: e870. doi: 10.14800/ccm.870.

Dickkopf-1 (Dkk-1) gene, "big head" in German, was originally discovered in Xenopus laevis as an embryonic head inducer and a potent antagonist of Wnt signaling ${ }^{[1]}$. In agreement, $D k k-1^{-/}$mice are embryonic lethal and lack head structures anterior to the mid-hindbrain boundary ${ }^{[2]}$. Human DICKKOPF1 (DKK-1) is the founding member of a family composed of four related genes, $D K K-1$ to 4 , and a close homologue called DKK-like protein 1 (DKKL1) ${ }^{[3]}$. DKK-1 encodes a secreted glycoprotein, DKK-1, of $37 \mathrm{kDa}$ with two conserved cystein-rich motifs ${ }^{[3]}$. DKK-1 binds to Wnt co-receptors LRP5 and LRP6 ${ }^{[4-7]}$ and inhibits the engagement of Wnt-Frizzled-LRP ternary complexes at the plasma membrane, thus avoiding $\mathrm{Wnt} / \beta$-catenin (also called canonical) signaling. DKK-1 also binds a second class of high affinity receptors, Kremen 1 and $2^{[8]}$. Kremen proteins form ternary complexes with DKK-1 and LRPs, which results in endocytosis of the complex and therefore removal of LRPs from the plasma membrane and inhibition of Wnt/ $\beta$-catenin signaling ${ }^{[8]}$. Kremen proteins are not universally required for DKK-1 function, as revealed in mice deficient in kremen genes ${ }^{[9]}$ and as shown by the capacity of DKK-1 to modulate canonical signaling via direct blocking of Wnt-LRP interactions ${ }^{[6]}$. Interestingly, $D K K-1$ not only encodes a Wnt antagonist but is also a $\beta$-catenin/TCF target gene ${ }^{[10-12]}$, and thus acts as a negative feedback regulator of the pathway. 
Wnt proteins perform a vast number of actions in organisms, both during development and in adult life ${ }^{[13]}$. As a Wht inhibitor, DKK-1 also affects numerous developmental processes such as body axis patterning or somitogenesis, as well as bone formation in the adult organism ${ }^{[14]}$. Remarkably, several authors have reported Wnt-independent actions of DKK-1. Expression of DKK-1 in $\beta$-catenin-deficient mesothelioma cell lines suppresses cell growth and induces apoptosis, apparently through activation of the c-Jun N-terminal kinase (JNK) pathway ${ }^{[15]}$. Likewise, DKK-1 induces apoptosis in human placental choriocarcinoma cells independently of $\mathrm{Wnt} / \beta$-catenin signaling and requires JNK activity ${ }^{[16]}$. JNK activation is also responsible for neurite formation in Ewing's sarcoma cells treated with DKK- ${ }^{[17]}$. Moreover, ectopic expression of DKK-1 in HeLa cervical carcinoma cell line results in decreased growth in soft agar and tumor formation in athymic mice independently of $\beta$-catenin/TCF transcriptional activity ${ }^{[18]}$. In breast cancer cell lines DKK-1 also has $\beta$-catenin-independent tumor suppressor effects which correlate with increased activity of $\mathrm{Ca}^{2+} /$ calmodulin-dependent protein kinase II pathway ${ }^{[19]}$. In line with these studies, we have reported Wnt-independent tumor suppressor effects of DKK-1 in colon carcinoma cells ${ }^{[20]}$. However, recent findings indicate that these cells can respond to exogenous and autocrine Wnt factors despite having mutations that stabilize $\beta$-catenin and thus the canonical pathway is activated intracellularly ${ }^{[21]}$. It is thus necessary to re-examine whether those effects are completely independent of canonical Wnt signaling. In summary, although accumulated evidence suggests that DKK-1 has functions other than inhibiting $\mathrm{Wnt} / \beta$-catenin signaling at the plasma membrane, this issue remains open at least in some systems.

The role of DKK-1 in human cancer is controversial. It has been shown to be both upregulated and downregulated depending on the type of tumor. The strongest evidence of DKK-1 overexpression comes from myeloma and hepatocellular carcinoma (HCC). Multiple myeloma is characterized by the appearance of osteolytic bone disease, which is due to augmented bone resorption by osteoclasts and reduced bone formation by osteoblasts. The levels of DKK-1 in serum of patients with multiple myeloma are higher than those in healthy controls and there is a good correlation with osteolytic bone disease ${ }^{[22]}$. Thus, there is mounting evidence that DKK-1 might be a good target for immunotherapy in myeloma patients ${ }^{[23]}$, and a recent study has demonstrated that active vaccination with DKK-1 induces protective antitumor immunity against multiple myeloma in rodents ${ }^{[24]}$. DKK-1 is also a diagnostic and prognostic serum marker in HCC ${ }^{[25-28]}$ and it promotes invasion and metastasis of HCC cells ${ }^{[27]}$. It has recently been shown that both DKK-1 and osteopontin enhance the diagnostic value of alpha-fetoprotein, the most widely used biomarker for HCC ${ }^{[29]}$. Other tumor types in which enhanced expression of DKK-1 has been reported include prostate, breast, gastric, ovarian, glioma, esophagic or pancreatic cancer ${ }^{[30-36]}$. Notably, high expression of DKK-1 frequently correlates with increased invasive and metastatic capacity of a variety of tumors ${ }^{[36-39]}$, which suggests that DKK-1 might be a metastasis promoter for some neoplasias. Moreover, in some cases DKK-1 levels fluctuate during cancer progression. Feldmann and colleagues showed that DKK-1 increases early in melanoma but then decreases in later tumor stages, which was interpreted as a sign of loss of tumor control ${ }^{[40]}$. Likewise, Hall and colleagues reported an early increase of DKK-1 expression levels in prostate cancer, which then diminished throughout progression from primary tumor to metastasis ${ }^{[41]}$.

DKK-1 is downregulated in a number of tumors, of which colon cancer is the most paradigmatic. We and others have reported reduced expression of DKK-1 in colon cancer ${ }^{[11,42]}$ that in a proportion of cases is associated with promoter hypermethylation ${ }^{[20,43,44]}$. This was an unexpected finding because as a $\beta$-catenin/TCF target $D K K-1$ gene was predicted to be upregulated in a malignancy characterized by a constitutively hyperactivated $\mathrm{Wnt} / \beta$-catenin pathway. Supporting these data, analysis of DKK-1 expression in human colon tumors demonstrated an inverse correlation with tumor grade, presence of metastasis, and recurrence ${ }^{[45]}$. Moreover, downregulation of DKK-1 expression is concomitant with reduced epithelial-to-mesenchymal transition (EMT) phenotype ${ }^{[45]}$, and with reduced angiogenesis and VEGF expression ${ }^{[42]}$. The complex behavior of DKK-1 as a tumor suppressor or metastasis promoter may rely on the diverse and sometimes opposite actions of $\mathrm{Wnt} / \beta$-catenin signaling in different tissues, together with other Wnt-independent effects that may add to the array of DKK-1 actions.

The recent demonstration by our group that DKK-1 is present within the nucleus of human enterocytes and colon cancer cells may help us to understand its biological functions ${ }^{[46]}$. Besides its expected localization in the cytoplasm and plasma membrane, DKK-1 protein has been found in the nucleus in a high proportion of differentiated cells (i.e. enterocytes and mucosecretory goblet cells) located in the upper half of colon and small intestine crypts. In the latter, nuclear DKK-1 expression was also detected in enteroendocrine cells at the bottom of the crypts. In contrast, stem cells at the bottom of the crypts and proliferating undifferentiated cells in the basal epithelia contained cytoplasmic but not nuclear DKK-1 in both colon and small intestine ${ }^{[46]}$. Moreover, new studies on DKK-1 expression in 


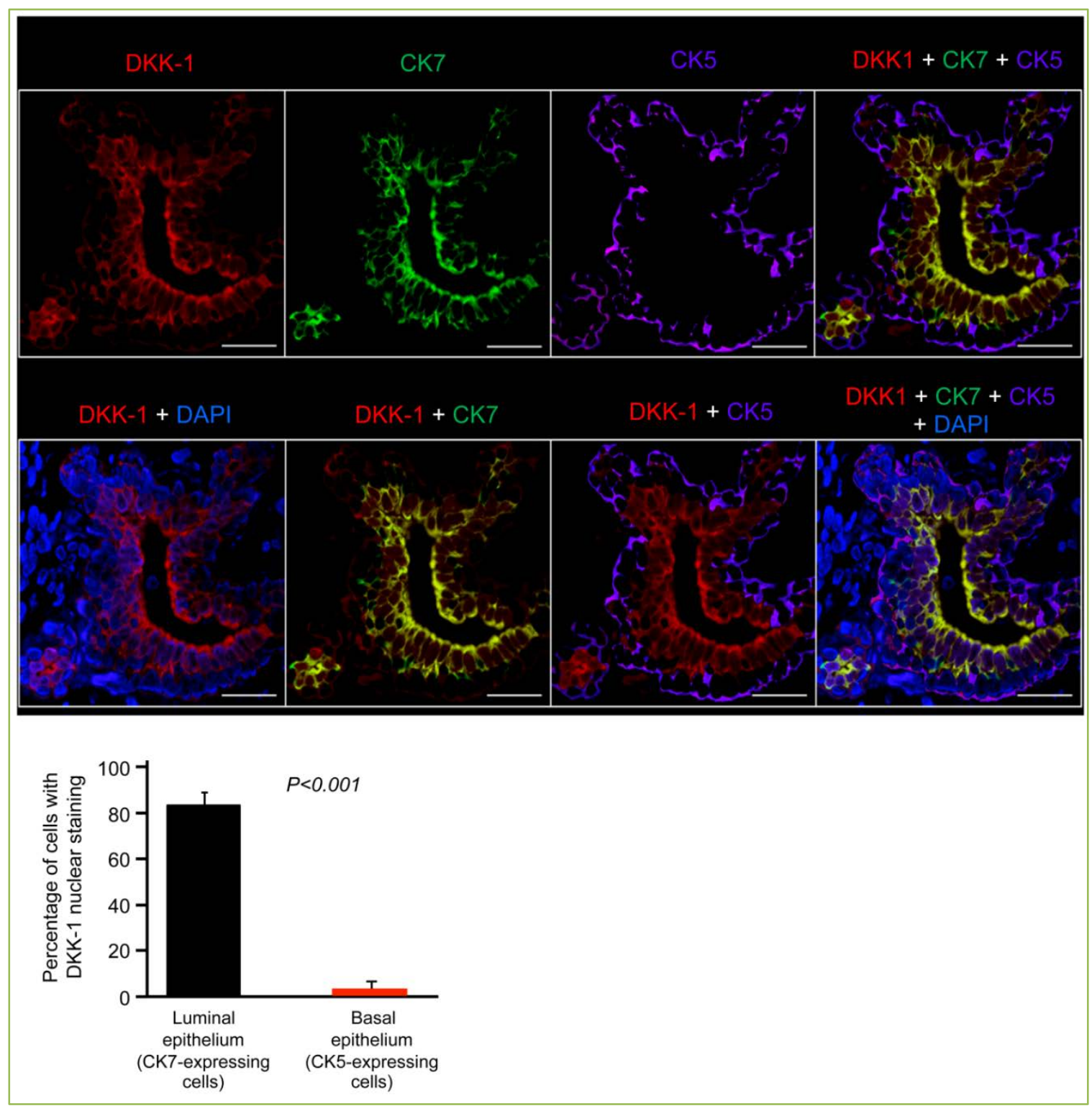

Figure 1. DKK-1 locates within the nucleus of human mammary luminal epithelial cells. Immunofluorescence images of DKK-1 (Ab: Cell Signaling Technologies, \#4687) expression in mammary glands that show nuclear location in CK7-positive luminal epithelial cells (Ab: Dako, clone OV-TL12/30) but not in CK5-positive basal myoepithelial cells (Ab: Santa Cruz Biotechnology, A-16). Cytoplasmic staining was diffuse in both luminal and basal cell layers. Scale bars: $25 \mu \mathrm{m}$. Nuclei were stained with DAPI. Images are representative from 120 randomly distributed microscopic fields from 12 non-tumoral mammoplasties. Quantification of cells showing nuclear DKK-1 staining is shown below the images.

the human mammary gland show that nuclear DKK-1 is present in $83.8 \%$ of differentiated cytokeratin (CK)7-positive luminal epithelial cells but almost absent (2.9\%) in CK5-positive basal and myoepithelial cells $(P<0.001)$ (Figure 1). Stromal cells in both intestine and mammary gland showed very low DKK-1 expression. This association between nuclear presence and differentiated cell stage suggests that nuclear DKK-1 could be involved in modulating the switch between proliferation and differentiation in the intestine and mammary gland epithelia. Nuclear DKK-1 binds to actively transcribed chromatin and regulates the expression of many genes, some of which are involved in cell proliferation, survival and stemness, and in xenobiotic defense ${ }^{[46]}$. In colon cancer, downregulation of nuclear DKK-1 at early steps of cancer progression is faster than that of DKK-1 outside the nucleus ${ }^{[46]}$. This favors the idea that DKK-1 within this compartment contributes, through regulation of its target genes, to the antiproliferative and global tumor suppressive action that is classically attributed to inhibition of Wnt signaling at the plasma membrane. Paradoxically, despite its protective effects in normal tissue and at early stages of progression, we have 


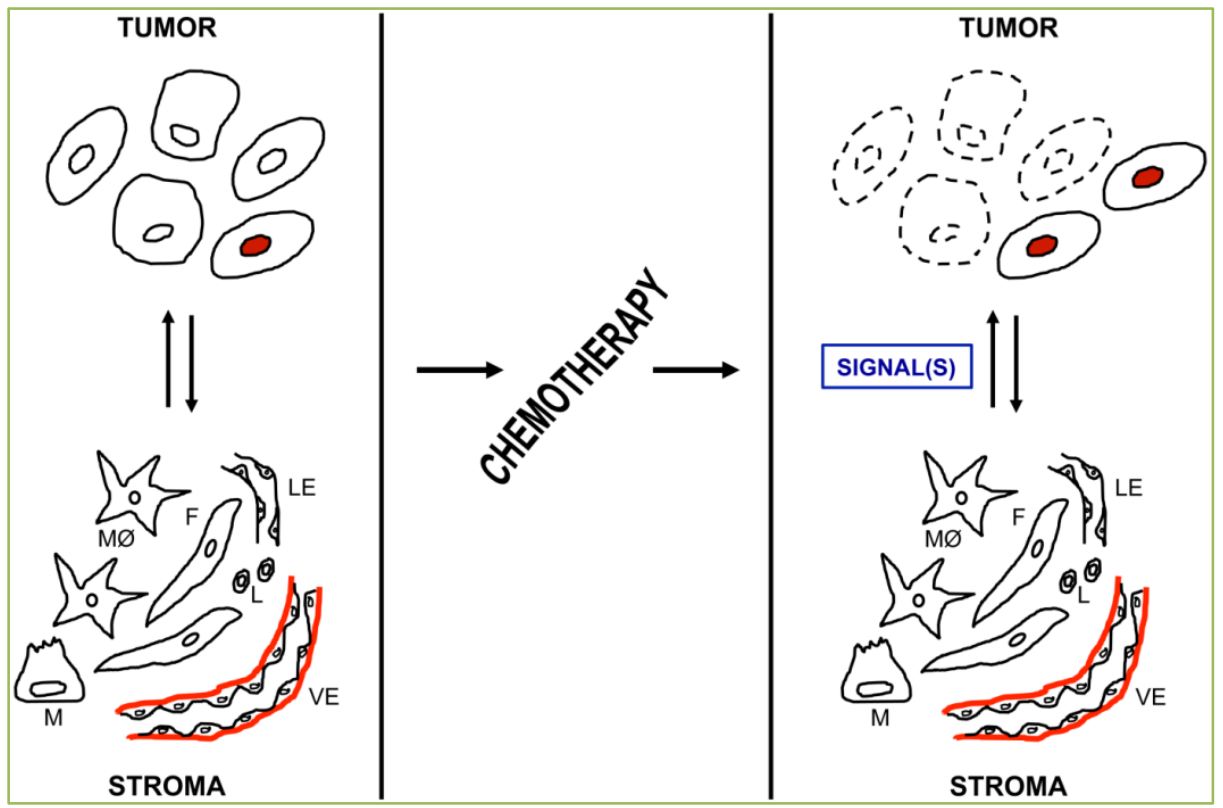

Figure 2. Schematic representation of the pattern of DKK-1 expression in human colon carcinoma cells during carcinogenesis. The putative role of the tumor environment in the nuclear accumulation of DKK-1 protein in carcinoma cells following chemotherapy is shown. Cells with nuclear DKK-1 expression are represented with solid red nuclei. Dying cells are represented with dashed lines. Stromal cells: macrophages (MФ), mastocytes (M). fibroblasts (F), lymphocytes (L), vascular endothelium (VE), lymphatic endothelium (LE).

shown that a proportion of colorectal carcinomas retain nuclear DKK-1 expression and this is associated with a resistance to chemotherapy. Upregulation of genes such as aldehyde dehydrogenase 1A1 (ALDH1A1) and Ral-binding protein 1-associated Eps domain-containing 2 (REPS2), which are involved in detoxification of chemotherapeutic agents, most probably explains this resistance to chemotherapy and lower survival rates of patients whose tumors express nuclear DKK-1 ${ }^{[46]}$. The presence of a proportion of DKK-1 protein in the nucleus regulating gene expression adds complexity to the proposed $\beta$-catenin-dependent and -independent mechanisms of action. It is thus necessary to re-evaluate previous studies based on the analysis of $D K K-1$ RNA or total cellular protein levels. Techniques to measure the subcellular localization of proteins such as immunohistochemistry, immunofluorescence or Western blotting of purified cellular fractions are required to yield an appropriate pattern of DKK-1 expression.

Finally, both the existence of a gradient in vivo in the level of nuclear DKK-1 along the intestinal crypts and of a higher amount of nuclear DKK-1 in tumor cells of chemoresistant colorectal cancer patients than those in cultured carcinoma cells ${ }^{[46]}$ suggest that nuclear accumulation of this protein is a non-cell-autonomous effect but, in contrast, is regulated by external signals probably coming from the stroma in normal tissue and from the tumor microenvironment in cancer patients (Figure 2). Given the role that nuclear DKK-1 appears to have for the response to chemotherapy in colon cancer ${ }^{[46]}$, identification of the nature and origin of such proposed signals is of utmost importance.

\section{Acknowledgements}

Work in authors' laboratories is supported by grants from Ministerio de Economía y Competitividad of Spain-Fondo Europeo de Desarrollo Regional (FEDER) (SAF2013-43468-R), Comunidad de Madrid (S2010/BMD-2344 Colomics2), and FEDER-Instituto de Salud Carlos III (RD12/0036/0021; RD12/0036/0051, PT13/0010/0012 and PI12/01552). The authors thank Robin Rycroft for his help with the English manuscript.

\section{References}

1. Glinka A, Wu W, Delius H, Monaghan AP, Blumenstock C, Niehrs C. Dickkopf-1 is a member of a new family of secreted proteins and functions in head induction. Nature 1998; 391:357-362.

2. Mukhopadhyay M, Shtrom S, Rodriguez-Esteban C, Chen L, Tsukui T, Gomer L, et al. Dickkopf1 is required for embryonic head induction and limb morphogenesis in the mouse. Dev Cell 2001; 1:423-434.

3. Krupnik VE, Sharp JD, Jiang C, Robison K, Chickering TW, Amaravadi L, et al. Functional and structural diversity of the human Dickkopf gene family. Gene 1999; 238:301-313. 
4. Mao B, Wu W, Li Y, Hoppe D, Stannek P, Glinka A, et al. LDL-receptor-related protein 6 is a receptor for Dickkopf proteins. Nature 2001; 411:321-325.

5. Bafico A, Liu G, Yaniv A, Gazit A, Aaronson SA. Novel mechanism of Wnt signalling inhibition mediated by Dickkopf-1 interaction with LRP6/Arrow. Nat Cell Biol 2001; 3:683-686.

6. Semënov MV, Tamai K, Brott BK, Kühl M, Sokol S, He X. Head inducer Dickkopf-1 is a ligand for Wnt coreceptor LRP6. Curr Biol 2001; 11:951-961.

7. Ahn VE, Chu ML, Choi HJ, Tran D, Abo A, Weis WI. Structural basis of Wnt signaling inhibition by Dickkopf binding to LRP5/6. Dev Cell 2011; 21:862-873.

8. Mao B, Wu W, Davidson G, Marhold J, Li M, Mechler BM, et al. Kremen proteins are Dickkopf receptors that regulate Wnt/beta-catenin signalling. Nature 2002; 417:664-667.

9. Ellwanger K, Saito H, Clément-Lacroix P, Maltry N, Niedermeyer $\mathrm{J}$, Lee WK, et al. Targeted disruption of the Wnt regulator Kremen induces limb defects and high bone density. Mol Cell Biol 2008; 28:4875-7882.

10. Niida A, Hiroko T, Kasai M, Furukawa Y, Nakamura Y, Suzuki $\mathrm{Y}$, et al. DKK1, a negative regulator of Wnt signaling, is a target of the beta-catenin/TCF pathway. Oncogene 2004; 23:8520-8526.

11. González-Sancho JM, Aguilera O, García JM, Pendás-Franco N, Peña C, Cal S, et al. The Wnt antagonist DICKKOPF-1 gene is a downstream target of beta-catenin/TCF and is downregulated in human colon cancer. Oncogene 2005; 24:1098-1103.

12. Chamorro MN, Schwartz DR, Vonica A, Brivanlou AH, Cho KR, Varmus HE. FGF-20 and DKK1 are transcriptional targets of beta-catenin and FGF-20 is implicated in cancer and development. EMBO J 2005; 24:73-84.

13. Hoppler S, Moon RT. Wnt signaling in develoment and disease: Molecular mechanisms and biological functions. Hoboken (NJ): John Wiley \& Sons; 2014.

14. Niehrs C. Function and biological roles of the Dickkopf family of Wnt modulators. Oncogene 2006; 25:7469-7481.

15. Lee AY, He B, You L, Xu Z, Mazieres J, Reguart N, et al. Dickkopf-1 antagonizes Wnt signaling independent of beta-catenin in human mesothelioma. Biochem Biophys Res Commun 2004; 323:1246-1250.

16. Peng S, Miao C, Li J, Fan X, Cao Y, Duan E. Dickkopf-1 induced apoptosis in human placental choriocarcinoma is independent of canonical Wnt signaling. Biochem Biophys Res Commun 2006; 350:641-647.

17. Endo Y, Beauchamp E, Woods D, Taylor WG, Toretsky JA, Uren A, et al. Wnt-3a and Dickkopf-1 stimulate neurite outgrowth in Ewing tumor cells via a Frizzled3- and c-Jun N-terminal kinase-dependent mechanism. Mol Cell Biol 2008; 28:2368-2379.

18. Mikheev AM, Mikheeva SA, Liu B, Cohen P, Zarbl H. A functional genomics approach for the identification of putative tumor suppressor genes: Dickkopf-1 as suppressor of HeLa cell transformation. Carcinogenesis 2004; 25:47-59.

19. Mikheev AM, Mikheeva SA, Maxwell JP, Rivo JV, Rostomily R, Swisshelm K, et al. Dickkopf-1 mediated tumor suppression in human breast carcinoma cells. Breast Cancer Res Treat 2008; 112:263-273

20. Aguilera O, Fraga MF, Ballestar E, Paz MF, Herranz M, Espada J, et al. Epigenetic inactivation of the Wnt antagonist DICKKOPF-1 (DKK-1) gene in human colorectal cancer. Oncogene 2006; 25:4116-4121.

21. Voloshanenko O, Erdmann G, Dubash TD, Augustin I, Metzig M, Moffa G, et al. Wnt secretion is required to maintain high levels of Wnt activity in colon cancer cells. Nat Commun 2013; 4:2610.

22. Heath DJ, Chantry AD, Buckle CH, Coulton L, Shaughnessy JD Jr, Evans HR, et al. Inhibiting Dickkopf-1 (Dkk1) removes suppression of bone formation and prevents the development of osteolytic bone disease in multiple myeloma. J Bone Miner Res 2009; 24:425-436.

23. Zhou F, Meng S, Song H, Claret FX. Dickkopf-1 is a key regulator of myeloma bone disease: opportunities and challenges for therapeutic intervention. Blood Rev 2013; 27:261-267.

24. Qian J, Zheng Y, Zheng C, Wang L, Qin H, Hong S, et al. Active vaccination with Dickkopf-1 induces protective and therapeutic antitumor immunity in murine multiple myeloma. Blood 2012; 119:161-169.

25. Tung EK, Mak CK, Fatima S, Lo RC, Zhao H, Zhang C, et al. Clinicopathological and prognostic significance of serum and tissue Dickkopf-1 levels in human hepatocellular carcinoma. Liver Int 2011; 31:1494-1504.

26. Shen Q, Fan J, Yang XR, Tan Y, Zhao W, Xu Y, et al. Serum DKK1 as a protein biomarker for the diagnosis of hepatocellular carcinoma: a large-scale, multicentre study. Lancet Oncol 2012; 13:817-826.

27. Tao YM, Liu Z, Liu HL. Dickkopf-1 (DKK1) promotes invasion and metastasis of hepatocellular carcinoma. Dig Liver Dis 2013; 45:251-257.

28. Yang H, Chen GD, Fang F, Liu Z, Lau SH, Zhang JF, et al. Dickkopf-1: as a diagnostic and prognostic serum marker for early hepatocellular carcinoma. Int J Biol Markers 2013; 28:286-297.

29. Ge T, Shen Q, Wang N, Zhang Y, Ge Z, Chu W, et al. Diagnostic values of alpha-fetoprotein, dickkopf-1, and osteopontin for hepatocellular carcinoma. Med Oncol 2015; 32:59.

30. Rachner TD, Thiele S, Göbel A, Browne A, Fuessel S, Erdmann $\mathrm{K}$, et al. High serum levels of Dickkopf-1 are associated with a poor prognosis in prostate cancer patients. BMC Cancer 2014; 14:649.

31. Zhou SJ, Zhuo SR, Yang XQ, Qin CX, Wang ZL. Serum Dickkopf-1 expression level positively correlates with a poor prognosis in breast cancer. Diagn Pathol 2014; 9:161.

32. Gao C, Xie R, Ren C, Yang X. Dickkopf-1 expression is a novel prognostic marker for gastric cancer. J Biomed Biotechnol 2012; 2012:804592.

33. Shizhuo W, Tao J, Shulan Z, Bing Z. The expression and significance of Dickkopf-1 in epithelial ovarian carcinoma. Int J Biol Markers 2009; 24:165-170.

34. Zhou Y, Liu F, Xu Q, Wang X. Analysis of the expression profile of Dickkopf-1 gene in human glioma and the association with tumor malignancy. J Exp Clin Cancer Res 2010; 29:138.

35. Begenik H, Kemik AS, Emre H, Dulger AC, Demirkiran D, Ebinc $\mathrm{S}$, et al. The association between serum Dickkopf-1 levels and esophageal squamous cell carcinoma. Hum Exp Toxicol 2014; 33:785-788.

36. Takahashi N, Fukushima T, Yorita K, Tanaka H, Chijiiwa K, Kataoka H. Dickkopf-1 is overexpressed in human pancreatic 
ductal adenocarcinoma cells and is involved in invasive growth. Int J Cancer 2010; 126:1611-1620.

37. Wang S, Zhang S. Dickkopf-1 is frequently overexpressed in ovarian serous carcinoma and involved in tumor invasion. Clin Exp Metastasis 2011; 28:581-591.

38. Thudi NK, Martin CK, Murahari S, Shu ST, Lanigan LG, Werbeck JL, et al. Dickkopf-1 (DKK-1) stimulated prostate cancer growth and metastasis and inhibited bone formation in osteoblastic bone metastases. Prostate 2011; 71:615-625.

39. Voorzanger-Rousselot N, Goehrig D, Journe F, Doriath V, Body JJ, Clézardin P, et al. Increased Dickkopf-1 expression in breast cancer bone metastases. Br J Cancer 2007; 97:964-970.

40. Feldmann R, Schierl M, Fink AM, Sator PG, Maiweg J, Steiner A. Serum levels of glycoprotein Dickkopf-1 in patients with cutaneous malignant melanoma: a prospective pilot study. Dermatology 2011; 222:171-175.

41. Hall CL, Daignault SD, Shah RB, Pienta KJ, Keller ET. Dickkopf-1 expression increases early in prostate cancer development and decreases during progression from primary tumor to metastasis. Prostate 2008; 68:1396-1404.
42. Liu Z, Sun B, Qi L, Li Y, Zhao X, Zhang D, et al. Dickkopf-1 expression is down-regulated during the colorectal adenoma-carcinoma sequence and correlates with reduced microvessel density and VEGF expression. Histopathology 2014; doi: 10.1111/his.12474.

43. Sato H, Suzuki H, Toyota M, Nojima M, Maruyama R, Sasaki S, et al. Frequent epigenetic inactivation of DICKKOPF family genes in human gastrointestinal tumors. Carcinogenesis 2007; 28:2459-2466.

44. Maehata $\mathrm{T}$, Taniguchi $\mathrm{H}$, Yamamoto H, Nosho K, Adachi Y, Miyamoto N, et al. Transcriptional silencing of Dickkopf gene family by CpG island hypermethylation in human gastrointestinal cancer. World J Gastroenterol 2008; 14:2702-2714.

45. Qi L, Sun B, Liu Z, Li H, Gao J, Leng X. Dickkopf-1 inhibits epithelial-mesenchymal transition of colon cancer cells and contributes to colon cancer suppression. Cancer Sci 2012; 103:828-835.

46. Aguilera Ó, González-Sancho JM, Zazo S, Rincón R, Fernández AF, Tapia O, et al. Nuclear DICKKOPF-1 as a biomarker of chemoresistance and poor clinical outcome in colorectal cancer. Oncotarget 2015; 6:5903-5917. 